Jurnal Infotekmesin Vol.9 No.1 Januari 2018

\title{
APLIKASI KAMUS INGGRIS - INDONESIA DENGAN FITUR SPEECH TO TEXT
}

\author{
Rima Anggraini ${ }^{1}$ Danuri $^{2}$, Agus Tedyyana ${ }^{3}$ \\ ${ }^{1,2,3}$ Program Studi Teknik Informatika, Politeknik Negeri Bengkalis \\ rimaanggraini9@gmail.com ${ }^{1}, \underline{\text { danuri@polbeng.ac.id }}{ }^{2}$, agustedyyana@polbeng.ac.id $^{3}$
}

\begin{tabular}{ll}
\hline & Abstrak \\
Kata Kunci: & $\begin{array}{l}\text { penggunaan kamus tidak hanya digunakan secara manual dengan mencari kata di buku kamus } \\
\text { Kamus, Speech to } \\
\text { Text, SQLite, Text }\end{array}$ \\
to Speech & $\begin{array}{l}\text { banyaknya aplikasi kamus saat ini maka dilakukan pengembangan dalam aplikasi kamus dengan } \\
\text { didutur speech to text dalam pencarian katanya. Pembuatan aplikasi ini menggunakan }\end{array}$ \\
& mencari arti kata, tapi juga terdapat daftar tensis yang dilengkapi dengan text to speech. Aplikasi ini \\
dapat mempermudah dalam mencari kata dan mengetahui tentang tensis. Hasil akhir dari aplikasi \\
ini telah diuji dengan beberapa smarthphone dengan versi android yang berbeda dan hasilnya aplikasi \\
ini dapat berjalan dengan baik. Kekurangan dari aplikasi ini adalah penggunaan fitur speech to text \\
yang masih online, dan data yang dapat dimasukkan kedalam SQLite tidak bisa banyak dan \\
terbatas, text to speech tidak dapat menjelaskan tensis dengan akurat.
\end{tabular}

\begin{tabular}{|c|c|}
\hline & Abstract \\
\hline $\begin{array}{l}\text { Keywords: } \\
\text { Kamus, Speech to } \\
\text { Text, SQLite, Text } \\
\text { to Speech. }\end{array}$ & $\begin{array}{l}\text { the use of dictionaries is not only used manually by searching for words in the dictionary book but also } \\
\text { digitally which facilitates the work in searching for the meaning of the word. Due to the number of } \\
\text { dictionary applications at this time it is done in the development of dictionary applications supported } \\
\text { speech to text features in the search he said. Making this application using SQLite database and editor } \\
\text { of Android Studio. The use of this dictionary not only functions in searching for the meaning of words, } \\
\text { but there is also a list of tensis that comes with text to speech. This application can make it easier to } \\
\text { find words and know about tensis. The end result of this application has been tested with several } \\
\text { smarthphone with different android version and the result of this application can run well. The } \\
\text { drawback of this application is the use of speech to text features that are still online, and data that can } \\
\text { be entered into SQLite can not be much and limited, text to speech can not explain tensis accurately. }\end{array}$ \\
\hline
\end{tabular}




\section{PENDAHULUAN}

Kamus adalah buku acuan yang memuat kata dan ungkapan yang biasanya disusun menurut abjad berikut keterangan tentang maknanya, pemakaiannya dan terjemahannya [1]. Penggunaan kamus saat ini telah digantikan dengan berbagai macam aplikasi, banyaknya pengembangan aplikasi yang terjadi menambah inovasi baru dengan juga menerapkan speech to text dalam pembuatan aplikasi.

Speech to text adalah bidang teknologi identifikasi ucapan manusia dalam bentuk teks. [7] Pengenalan pola suara adalah salah satu aplikasi yang berkembang saat ini.

Kamus saat ini berkembang dengan menggunakan buku. Penggunaan buku kamus saat ini dengan cara membuka buku dan mencari satu persatu sesuai abjad huruf awal kata yang ingin dicari dan harus membolak balikkan kertas yang ada pada buku, sehingga kata yang ingin dicari menggunakan kamus akan menghabiskan banyak waktu dan kurangnya kecepatan dalam menyelesaikan pencarian arti kata. Selain penggunaan buku kamus terdapat pula aplikasi aplikasi yang mampu bekerja layaknya buku kamus, tetapi penggunaan aplikasi ini akan lebih mempermudah dalam pencarian kata dan akan mempersingkat waktu dalam pencariannya. Sehingga perkembangan aplikasi kamus semakin banyak. Salah satu perkembangan aplikasi ini menggunakan speech to text. Penerapan speech to text akan memaksimalkan peforma aplikasi kamus. Dengan demikian penggunaan speech to text akan menggantikan tugas pengetikan dalam mencari kata sehingga kecepatan dalam mencari kata semakin lebih cepat

\section{A. Rumusan Masalah}

Berdasarkan latar belakang diatas maka dapat dirumuskan bagaimana membuat aplikasi kamus Bahasa Inggris ke Bahasa Indonesia dilengkapi dengan fitur speech to text yang dijalankan pada platform Android.

\section{B. Batasan Masalah}

Berdasarkan rumusan masalah yang telah dijelaskan maka dapat ditentukan batasan masalah dalam pembangunan aplikasi ini:

1. Bahasa Pemograman yang digunakan adalah bahasa java.

2. Menggunakan Google Cloud Speech API.

3. Hasil terjemahan hanya dapat ditampilkan dalam bentuk kata bukan kalimat.
Tujuan dari peneltian ini adalah membangun sebuah aplikasi kamus bahasa Inggris ke bahasa Indonesia dengan menggunakan fitur speech to text yang bisa dijalankan pada platform Android.

Manfaat yang didapat dari penelitian ini yang akan dirasakan para penggunanya yang sebagian besar merupakan mahasiswa maupun pelajar adalah

1. untuk mempermudah pekerjaan dalam mencari arti dari sebuah kata yang tidak diketahui.

2. Tidak perlu mengetik dalam mencari kata

\section{LANDASAN TEORI}

\section{A. Kamus}

Kamus adalah buku acuan yang memuat kata dan ungkapan, biasanya disusun menurut abjad berikut keterangan tentang makna, pemakaian, atau terjemahannya buku yang memuat kumpulan istilah atau nama yang disusun menurut abjad beserta penjelasan tentang makna dan pemakaiannya. Kamus yang memuat kata-kata yang digunakan dalam berbagai - bagai ragam bahasa dengan keterangan makna dan penggunaannya, dengan menghindarkan istilah teknis atau kata yang digunakan dalam lingkungan terbatas, dengan kata lain kamus menggambarkan ragam bahasa baku. Kamus menjadi acuan untuk karya yang sejenis. [1]

\section{B. Android}

Android adalah sistem operasi mobile berdasarkan modifikasi versi Linux. Android awalnya dikembangkan oleh sebuah perusahaan pengembang yang namanya sama, Android, Inc. pada tahun 2005, sebagai bagian strateginya dalam memasuki pasar mobile, Google membeli Android dan mengambil alih pengembanganya sampai sekarang. [6]

Android telah mengalami sejumlah update sejak pertama kali diluncurkan pada tahun 2007 sampai yang diluncurkan terkahir tahun 2013. Kode nama versi Android menggunakan nama-nama kue agar mudah diingat

\section{Speech To Text}

Speech to Text merupakan salah satu dari speech recognition dimana speech recognition ini adalah proses pengkonfersian suara menjadi output digital salah satunya adalah teks. Speech to Text menggunakan library Google Speech API.

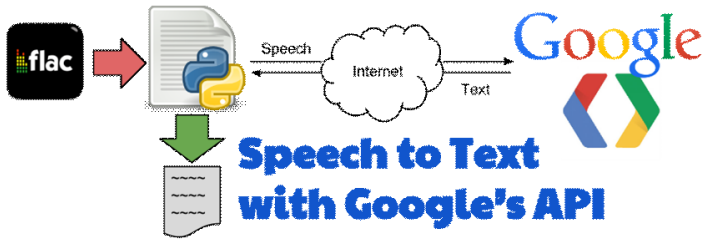

Gambar 1. Proses Speech to Text

\section{Tujuan dan Manfaat}


Google Speech API adalah sebuah framework yang dikembangkan oleh Google untuk mengenali suara, mengubahnya menjadi string (teks) dan memasukkanya ke dalam halaman pencarian Google sehingga akan tampil hasil pencarian berdasarkan input suara. Pengenalan suara dilakukan pada server Google menggunakan algoritma Hidden Markov Model (HMM). Dengan kata lain input suara yang diterima oleh perangkat Android (smartphone) akan dikirimkan ke server Google, yang selanjutnya server Google melakukan pengenalan dan mengubahnya menjadi teks menggunakan algoritma HMM. Hasil konversi suara menjadi teks kemudian dimasukkan dalam halaman pencarian Google kemudian server Google akan mengirimkan hasil pencarianya tersebut ke perangkat Android [6]

\section{Android Studio}

Android studio adalah IDE (Integrated Development Environment) resmi untuk pengembangan aplikasi Android dan bersifat open source atau gratis. Peluncuran Android Studio ini diumumkan oleh Google pada 16 mei 2013 pada event Google I/O Conference untuk tahun 2013. Sejak saat itu, Android Studio mengantikan Eclipse sebagai IDE resmi untuk mengembangkan aplikasi Android. [3]

\section{E. Bahasa Pemograman Java}

Bahasa pemrograman java merupakan salah satu bahasa pemrograman umum (general purpose programming language) berorientasi objek yang pertama kali diluncurkan pada tahun 1990-an oleh James Gosling dan Sun Microsistem [2].

\section{F. Unified Modeling Language (UML)}

Unified Modelling Language (UML) adalah sebuah "bahasa" yang telah menjadi standar dalam industri untuk visualisasi, merancang dan mendokumentasikan sistem piranti lunak. [5]

Notasi standar yang disediakan UML bisa digunakan sebagai alat komunikasi bagi para pelaku dalam proses analisis yaitu salah satunya adalah diagram use case.

Diagram use case merupakan pemodelan untuk kelakuan (behavior) sistem informasi yang akan dibuat. Use case mendeskripsikan sebuah interaksi antara satu atau lebih aktor dengan sistem informasi yang akan dibuat [4]

\section{PERANCANGAN}

\section{A. Prosedur Penelitian}

Metode yang digunakan dalam menyelesaikan masalah ini adalah dengan menggunakan tahapan - tahapan yang dapat memastikan upaya penelitian dan perancangan aplikasi akan mencapai hasil yang maksimal.

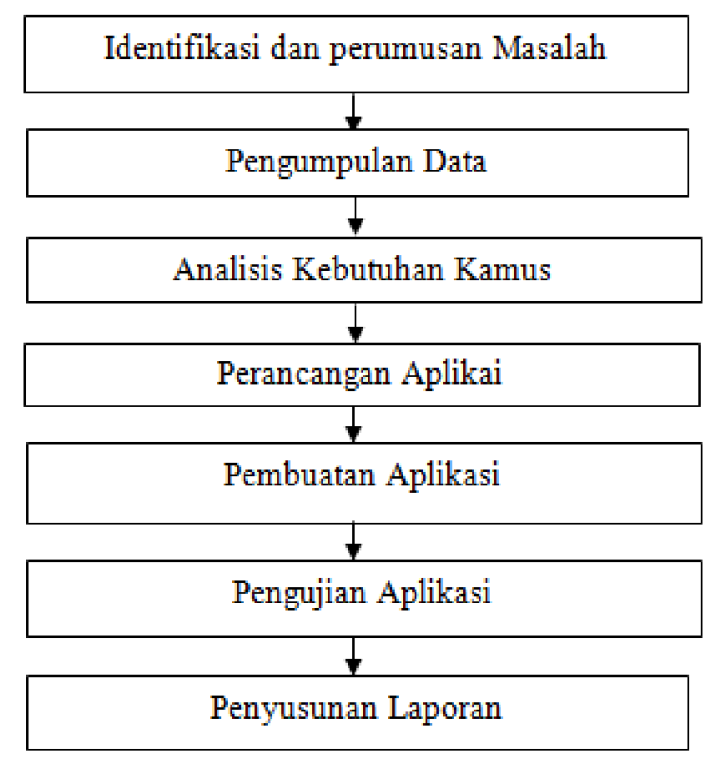

Gambar 2. Prosedur Penelitian

Tahapan Penelitian dapat dijelaskan sebagai berikut:

1. Identifikasi Masalah

Pada tahapan ini merupakan langkah mengidentifikasi masalah. Dan permasalahan yang telah diidentifikasi berdasarkan perumusan masalah.

2. Pengumpulan Data

Pada tahapan ini merupakan langkah mengumpulkan data dengan metode Study Literature dan penyebaran angket. Literatur yang digunakan adalah berupa artikel-artikel baik dari internet maupun jurnal serta datadata penelitian dan percobaan yang telah dilakukan sebelumnya. Angket yang diberikan kepada 5 orang mahasiswa yang ada di bengkalis.

3. Analisis Kebutuhan Aplikasi

Pada tahap ini dibuatlah sebuah proses analisa pada data-data yang akan dibutuhkan dalam pembuatan aplikasi dan data - data yang terkumpul akan diproses secara lebih lanjut.

4. Perancangan Aplikasi

Pada tahapan ini dilakukan perancangan aplikasi dalam tampilan dan merancang bagaimana proses yang akan berjalan pada apliasi yang akan diusulkan

5. Pembuatan aplikasi

Pada tahapan ini dilakukan pembuatan program Aplikasi Kamus Inggris Indonesia Dengan Fitur Speech To Text yaitu pengkodingan, mendesain aplikasi dan kebutuhan fungsionalitas lainnya. 
6. Pengujian aplikasi

Pada tahapan ini dilakukan tahapan pengujian. Pengujian ini dilakukan untuk memastikan bahwa kinerja dari sistem dapat berfungsi sesuai yang diharapkan.

7. Penyusunan laporan

Penyusunan Laporan penelitian ini terdiri dari

\section{BAB I PENDAHULUAN \\ 2.BAB II TINJAUAN PUSTAKA \\ 3.BAB III PERANCANGAN \\ 4.BAB IV HASIL DAN PENGUJIAN \\ 5.BAB V PENUTUP}

\section{B. Analisa Sistem yang Sedang Berjalan}

Saat ini sistem yang sedang berjalan menggunakan buku kamus dengan cara mencari kata bahasa inggris dengan melihat huruf awal dari kata tersebut dan sesuaikan huruf tersebut pada abjad yang tersedia dalam buku kamus.

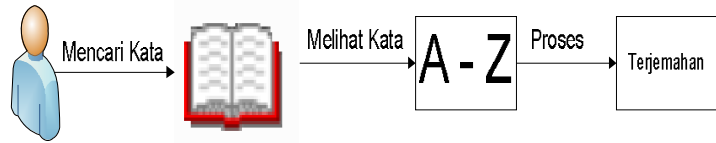

Gambar 3. Sistem yang Berjalan Pada Kamus

Selain itu pula terdapat aplikasi yang bisa digunakan dalam mencari arti kata bahasa inggris dengan mengetikkan kata yang di inginkan lalu dapat dilihat langsung apa arti dari kata tersebut.

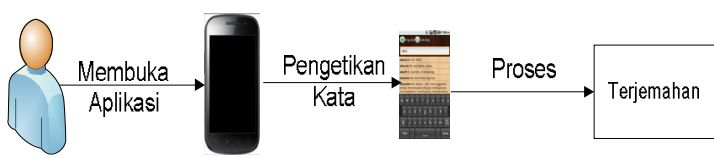

Gambar 4. Sistem yang Berjalan Pada Aplikasi

1. Analisa Sistem yang Diusulkan

Sistem yang akan diusulkan adalah sebuah aplikasi kamus yang bisa menggunakan suara sebagai pencarian kata yang dapat dirubah menjadi teks lalu teks tersebut dapat langsung diterjemahkan kedalam Bahasa Indonesia. Sistem ini dapat dilihat melalui gambar dibawah ini yang menjelaskan bagaimana cara kerja dari aplikasi yang akan dibuat.

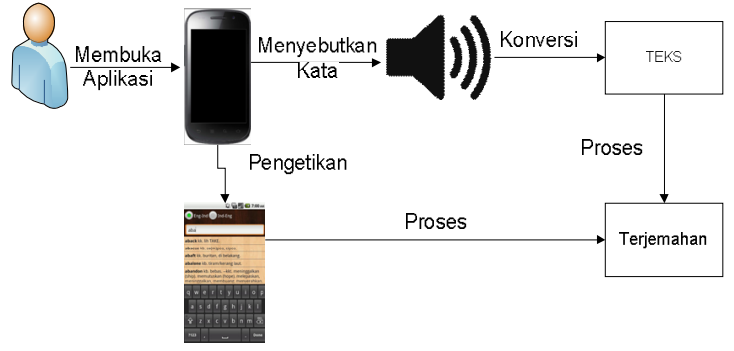

Gambar 5. Perancangan Sistem yang diusulkan

\section{Usecase Diagram Sistem}

Bentuk dari diagram usecase yang akan digunakan pada pembuatan aplikasi ini akan dijelaskan pada gambar 3.4

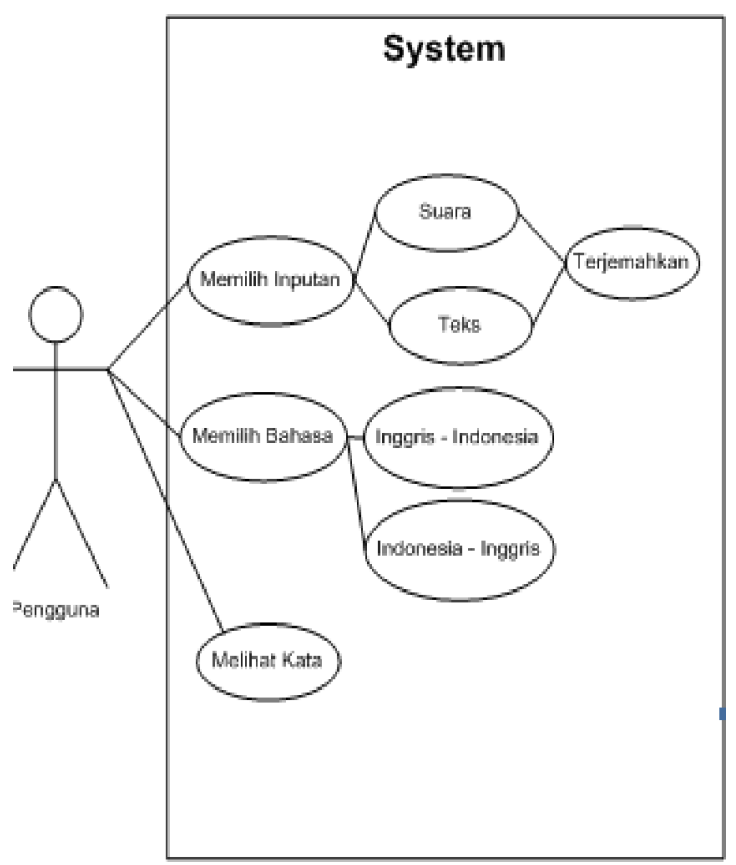

Gambar 6. Usecase Diagram

1. Aktor yang berperan adalah Pengguna

2. Usecase melihat kata. Usecase ini mendeskripsikan tentang user bisa melihat kata -kata yang ada didalam kamus

3. Usecase memilih inputan. Usecase ini mendeskripsikan bahwa user bisa memilih inputan dengan menggunakan pengucapan suara atau melalui pengetikan teks melalui keypad. Kemudian kata tersebut dapat diterjemahkan sesuai bahasa yang dipilih

4. Usecase memilih bahasa. Usecase ini mendeskripsikan tentang user bisa memilih penginputan data baik itu dari bahasa Indonesia ke Inggris maupun Inggris ke Indonesia

\section{HASIL DAN PEMBAHASAN}

Hasil dari penelitian ini berupa sebuah aplikasi kamus inggris - indonesia dengan fitur speech to text, tidak hanya mengartikan kata, tetapi juga dilengkapi dengan kumpulan tensis yang didukung dengan fitur teks to speech. Dengan menggunakan bahasa pemograman java dan editor Android Studio.

A. Hasil Perancangan Antar Muka

Pada halaman utama pada aplikasi kamus ini terdapat berbagai pilihan menu diantaranya ada 
menu Kamus, Tensis, Tentang dan Keluar seperti pada gambar 7 dibawah ini.

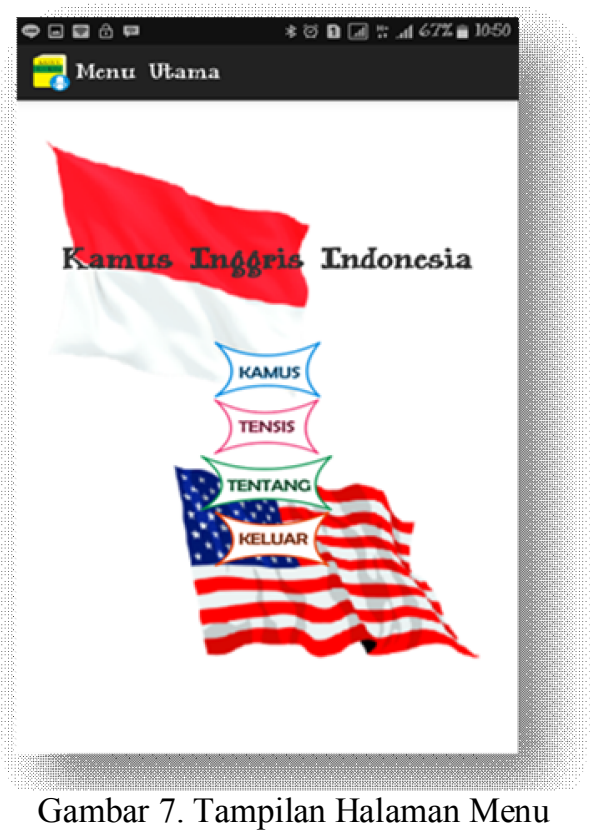

Pada pilihan menu kamus akan ditampilkan pilihan bahasa indonesia ke inggris atau inggris ke indonesia yang jika dipilih akan masuk ke dalam halaman terjemahannya. Disini akan ada tombol mikrophon dan tombol search yang dapat digunakan untuk mencari arti kata yang di inginkan.

Pilihan untuk menginput data menggunakan tombol mikrophone yang akan menampilkan proses untuk menginput suara dengan menggunakan Google Speech API.

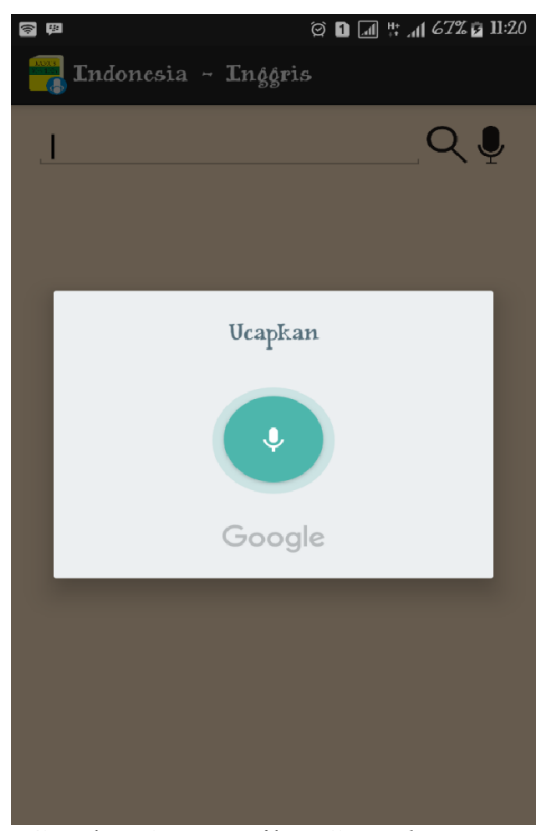

Gambar 8. Tampilan Speech to Text
Pilihan untuk tombol search adalah untuk mencari kata dengan menggunakan pengetikan pada keypad smarthphone.

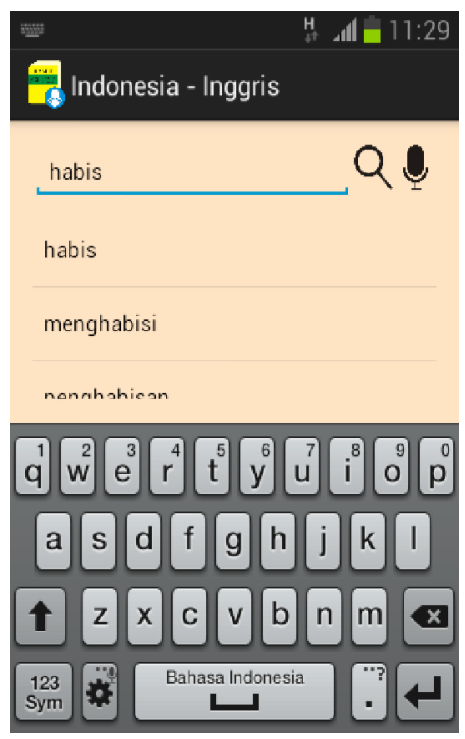

Gambar 9. Tampilan Search Dengan Pengetikan

Setelah proses pencarian pada kata pengguna dapat memilih kata yang diinginkan yang terdapat pada daftar katanya. Maka akan keluar halaman keterangan atau halaman arti.

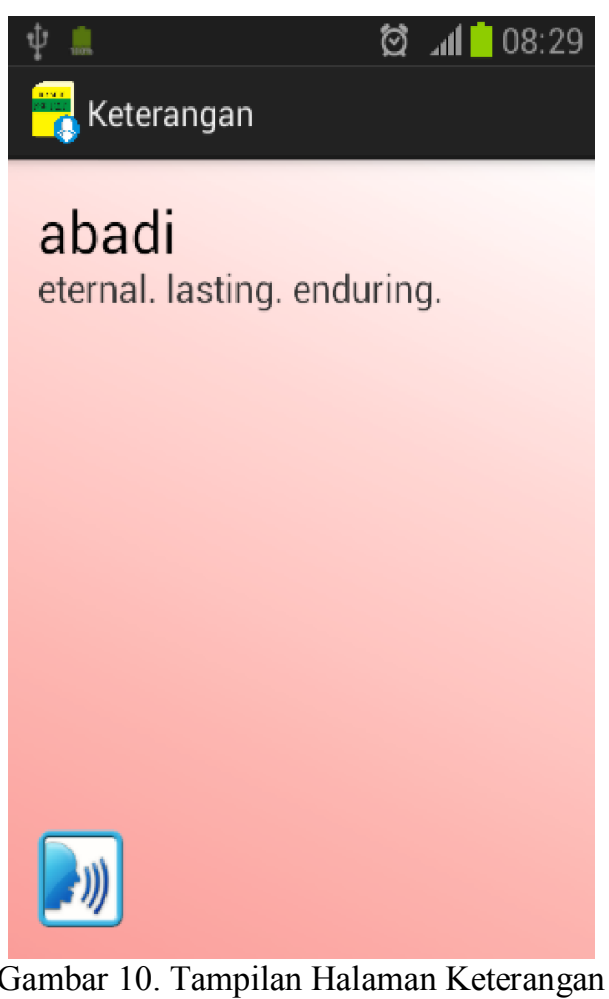

Pada menu tensis akan menampilkan daftar dari Past tense, dan Present Tense yang dapat dipilih oleh pengguna. 


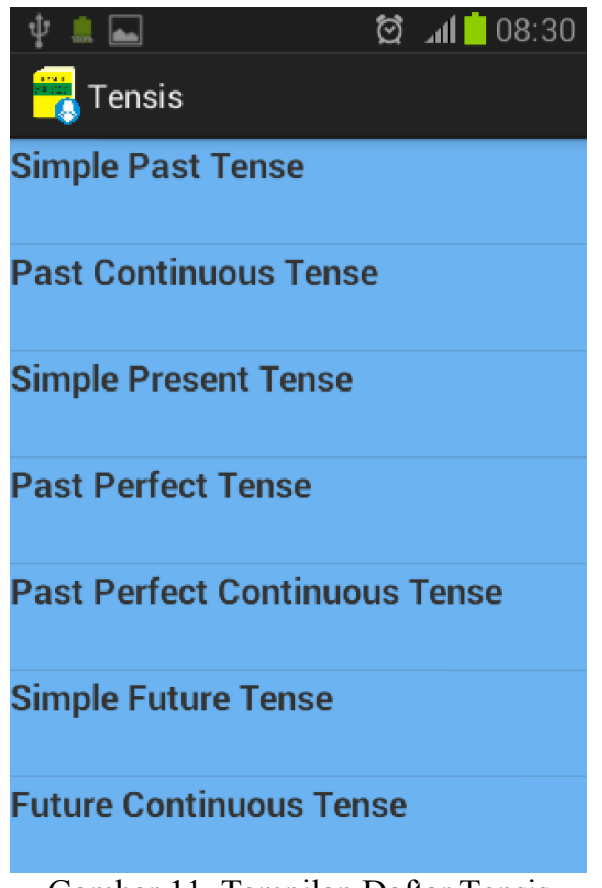

Gambar 11. Tampilan Daftar Tensis

Pada setiap daftar dari tensis ini bisa dipilih dan akan menampilkan penjelasan tentang tensis yang dipilih. Dalam halaman ini akan ada tombol Baca untuk membaca tulisan yang ada pada halaman tersebut dengan menggunakan fitur text to speech.

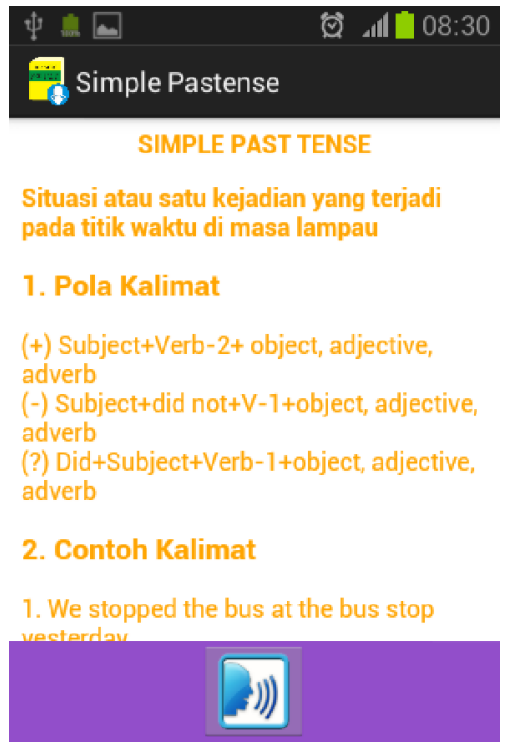

Gambar 12. Tampilan Isi Tensis

Pilihan menu Keluar berfungsi untuk keluar dari aplikasi kamus ini, yang menandakan akhir dari sesi kamus ini akan ada pilihan antara ya dan tidak. Jika ya artinya keluar dari aplikasi jika memilih tidak maka akan tetap ada di aplikasi

\begin{tabular}{|c|c|c|c|}
\hline \multirow[t]{2}{*}{ No } & \multicolumn{2}{|c|}{ Spesifikasi Perangkat Android } & \multirow[t]{2}{*}{ Hasil Pengujian } \\
\hline & OS & LCD & \\
\hline 1. & $\begin{array}{l}\text { Android 4.1.2 } \\
\text { (Jelly Bean) }\end{array}$ & 3.5 inch & $\begin{array}{l}\text { - Tampilan Responsive } \\
\text { - Speech To Text Berhasil (Online) } \\
\text { - Suara berhasil } \\
\text { - Terjemahan Berhasil }\end{array}$ \\
\hline 2 & $\begin{array}{l}\text { Android 4.4.2 (Kit } \\
\text { Kat) }\end{array}$ & 4 inch & $\begin{array}{l}\text { - Tampilan Responsive } \\
\text { - Speech To Test Berhasil (Online) } \\
\text { - Terjemahan Berhasil } \\
\text { - Suara Berhasil }\end{array}$ \\
\hline 3. & $\begin{array}{l}\text { Android } \\
\text { 5.0.(Lollipop) }\end{array}$ & $\begin{array}{l}4.3 \\
\text { Inch }\end{array}$ & $\begin{array}{l}\text { - Tampilan Responsive } \\
\text { - Speech To Text Berhasil (Online) } \\
\text { - Terjemahan Berhasil } \\
\text { - Suara Berhasil }\end{array}$ \\
\hline 5. & $\begin{array}{l}\text { Android 6.0.1 } \\
\text { (Marshmallow) }\end{array}$ & $\begin{array}{l}5.2 \\
\text { Inch }\end{array}$ & $\begin{array}{l}\text { - Tampilan Responsive } \\
\text { - Speech To Text Berhasil (Online) } \\
\text { - Terjemahan Berhasil } \\
\text { - Suara Berhasil }\end{array}$ \\
\hline
\end{tabular}

Hasil dari pengujian aplikasi ini adalah aplikasi mampu berjalan dengan baik menggunakan sistem operasi android dari versi jelly bean hingga ke marshmellow. Selain itu pula penggunaan fitur speech to text diharuskan untuk online dan semakin jauh jarak suara dari aplikasi maka akan mempengaruhi hasil inputan suara sehingga kata yang di konversikan bisa terjadi kesalahan seperti kata yang keluar tidak sesuai dengan yang diucapkan.

\section{KESIMPULAN}

Dari hasil penelitian Aplikasi Kamus Inggris Indonesia Dengan Fitur Speech to Text yang telah 
dirancang dapat disimpulkan aplikasi ini mampu melakukan inputan kata dengan menggunakan suara dengan adanya fitur dai google speech api. Penkonversian suara ke teks ini disarankan untuk memiliki suara yang jelas karena kejelasan suara akan mempengaruhi dari konversian suara. Selain suara yang jelas diharuskan penggunaan jaringan secara online yang stabil agar proses jalan dari speech to text ini dapat berjalan dengan lancar. Kemudian pengguna dapat melihat berbagai macam tensis yang didalamnya terdapat fitur Text to Speech. Aplikasi ini dapat berjalan pada Android veri 4.1.2 hingga versi 6.0.1. Perancangan sistem menggunakan UML, bahasa pemrograman Java dan database SQLite.

Dari kesimpulan yang dijelaskan, maka dapat didiambil beberapa saran untuk melakukan pengembangan dari aplikasi kamus ini kedepannya. Sistem Aplikasi ini masih diharuskan online untuk menjalankan fitur speech to text. Kedepannya diharapkan agar penggunaan speech to text tidak lagi secara online tetapi secara offline.

Penggunaan database SQLite bisa memiliki data banyak tetapi proses jalannya aplikasi akan semakin lambat. Semakin banyaknya data yang ada pada aplikasi maka proses dari penginstalan aplikasi ini semakin lama.

\section{Daftar Pustaka :}

[1] Ebta Setiawan., 2012 - 2016, KBBI Online, Website : http://kbbi.web.id/, diakses tanggal 02 - Desember - 2016

[2] Irawan., 2007. Java Untuk OrangAwam. Palembang : Maxikom.

[3] Juansyah., 2015, Pembangunan Aplikasi Child Trackerberbasis Assisted - Global Positioning System(A - Gps) Dengan Platform Android, Jurnal Ilmiah Komputer dan Informatika (KOMPUTA), Edisi. 1, Volume. 1, ISSN : $2089-9033$

[4] Sukamto, Shalahuddin, Rekayasa Perangkat Lunak, Bandung: Informatika, 2013.

[5] Sulistyorini, 2009, Pemodelan Visual dengan Menggunakan UML dan Rational Rose, Jurnal Teknologi Informasi DINAMIK Volume XIV, No.1, Januari 2009 ISSN: 0854-9524 hal: 23-29

[6] Supriyanta, Widodo., 2016, Aplikasi Konversi Suara Ke Teks Berbasis Android Menggunakan Google Speech API, Indonesian Journal on Networking and Security. Volume 5 No 2, ISSN : $2302-$
5700 (Print) - 2354-6654 (Online), hal. 21 25

[7] Yuwono, Antonio, 2015, Studi Format Audio dan Teks Untuk Modul Speech to Text, JUISI, Vol. 01, No. 01, hal. $11-20$, ISSN: $2460-1306$ 